\title{
Narración y desarrollo cognitivo: el potencial didáctico de una alianza neurolingüística
}

\author{
Delia María Fajardo Salinas \\ Universidad Pedagógica Nacional Francisco Morazán \\ Palabras clave: $<$ Interculturalidad $><$ Narración $><$ Desarrollo \\ cognitivo $><$ Competencia intercultural $>$
}

Este artículo argumenta por qué el uso de la literatura de Tradición Oral de los pueblos indígenas y afrodescendientes es la herramienta didáctica idónea para diseñar propuestas curriculares fundamentadas en el enfoque intercultural. Para ello, primero se hace una breve referencia a la discusión en torno al concepto de interculturalidad y se especifica la posición teórica que se asume para dicha argumentación; luego, se hace una revisión de los estudios sobre la narración como forma literaria y como estructura neurolingüística, y, por último, una recopilación de estudios que demuestran la relevancia de las narraciones en la maduración psicológica de niñas y niños.

\section{Introducción}

En América Latina, la discusión sobre el concepto de interculturalidad y su aplicación en el campo educativo es sumamente relevante en el contexto actual de la globalización, las crisis socioeconómicas generadas por el modelo neoliberal, las estrategias para estabilizar el sistema democrático de gobierno, y el contra peso de las gestiones políticas por el reconocimiento de la diversidad cultural y lingüística de pueblos indígenas y afrodescendientes, con el consecuente reconocimiento y respeto de sus derechos sociales, culturales y lingüísticos.

De hecho, la lucha que se despliega en el campo político y educativo entre la clase en el poder y los grupos subalternos tiene su expresión discursiva en la forma en que se define la interculturalidad: por un lado, como una nueva etiqueta para las políticas indigenistas de carácter asistencialista, $y$, por otro, como un instrumento para fundamentar

<PARADIgMA> - Revista de Investigación Educativa. Año 20. No. 31 
el reclamo del poder compartido. En palabras de Sartorello:

“a) Uno funcional al modelo de estado-nación neoliberal que, siguiendo la tradición del multiculturalismo anglosajón (Taylor, 1993), concibe las políticas interculturales como mecanismos asistenciales que contribuyan al proceso de integración - subordinada - de los grupos tradicionalmente excluidos de las políticas públicas del Estado (entre ellos los pueblos indígenas).

b) Otro crítico del sistema político y económico neoliberal que, desde una visión altermundista, considera que la interculturalidad en general y la educación intercultural bilingüe en lo específico son un derecho y un medio para lograr la reproducción de las culturas en minoría y en condición subalterna." (Sartorello, 2009).

En esta lid, la arena educativa es un campo de lucha simbólica crucial porque atañe a la formación ideológica de los ciudadanos. Dependiendo de las creencias, principios morales, posiciones políticas que se forjen en la mentalidad de las personas, éstas asumirán una inclinación por una línea teórica y una manera de relacionarse con la diversidad que definirá a su vez su tipo de participación en la dinámica social.

Es de nuestro interés en este artículo abogar por un concepto de interculturalidad desde la postura crítica, para fundamentar un enfoque curricular a favor de las expectativas que dicha manera de entender la interculturalidad conlleva: la construcción de una estructura de relaciones en un plano de horizontalidad, equidad, curiosidad positiva por la otredad, respeto mutuo, propiciadora de la negociación-mediación-conciliación, generadora de nuevos aprendizajes culturales y de la ocurrencia de cambios en la propia visión de mundo, entendidos como enriquecimiento. Esta estructura de relaciones se fundamenta además en una postura crítica con respecto a situaciones de discriminación y/o conflicto entre pueblos étnicos, con el propósito de rechazarlas, denunciarlas y solventarlas. Por lo tanto, nos posicionamos en una definición contra hegemónica del concepto 'interculturalidad', que se construye desde el movimiento indígena y afrodescendiente y desde la sociedad civil, para cuestionar 
y neutralizar el carácter asistencialista del que se publicita desde el Estado y sus dependencias puesto que lo descontextualizan del nicho de problemas de inequidad e irrespeto de los derechos humanos en que se dan las relaciones con estos grupos sociales subalternos al campo de poder.

Partiendo de esta posición, hemos intentado elaborar una fundamentación para construir una herramienta didáctica que sea coherente con este enfoque curricular intercultural. Dicha herramienta es el uso de relatos propios de la Tradición Oral de los pueblos indígenas y afrodescendientes en la educación básica. Partimos de un breve estudio sobre la narración tanto como forma literaria como estructura neurolingüística; continuamos con los estudios sobre las funciones educativas de las narraciones en la infancia y finalizamos describiendo el potencial que, en particular, la literatura de Tradición Oral ofrece para los proyectos de educación intercultural, cuyo núcleo curricular debe ser la formación de la competencia intercultural.

\section{La Narración: historia de una forma}

La presencia de la narración como estructura comunicativa en la historia y evolución del ser humano como especie, le acompaña desde siempre. Recordemos las pinturas rupestres, las muestras artísticas más antiguas que se conocen y que han existido en todas las latitudes donde se ha registrado presencia humana desde los tiempos prehistóricos. Constituyen un sistema de representación simbólica, iconográfico, que esas comunidades primitivas utilizaron para relatar las actividades propias de su relación con el entorno. Seguramente, la imagen más común que asoma en nuestra mente es la caza de mamuts, pero las pinturas rupestres también cuentan las costumbres de la vida doméstica, la recolección de alimento, la relación con los dioses. Se asume que estas primeras expresiones simbólicas de la mente humana conllevaron una funcionalidad espiritual, en muchos casos claramente ritual.

Por ello, la siguiente manifestación donde se reconoce la presencia de formas narrativas es en los rituales y los mitos. Al respecto, en su estudio sobre las raíces del cuento maravilloso, Vladimir Propp (1979) concluye que una vez que la funcionalidad religiosa desapareció, quedaron los relatos obedeciendo más a impulsos meramente 
socializadores o artísticos.

Pero antes de Propp, y como ocurre en todo el conocimiento científico y filosófico occidental, es en los griegos donde encontramos las primeras formulaciones teóricas sobre la narración: tanto Platón como Aristóteles se interesaron en la explicación de los usos lingüísticos utilizados para la representación de las acciones y las pasiones humanas, y de ellos heredamos las nociones de mimesis (como imitación directa de la realidad) y diégesis (cuando la realidad se refiere por el relato de un narrador) (Adam y Lorda, 1999: 17-21, 34).

Fue a lo largo del siglo XX que los estudios sobre la narración en la creación literaria experimentaron una atención exponencial que luego rebasó este campo. Siguiendo el sucinto recorrido de Adam y Lorda sobre esta evolución, y después del antecedente ya referido a los clásicos, estos lingüistas señalan que el impulso dominante vino con el Estructuralismo, siendo la "Morfología del Cuento" (1928) la obra fundacional de esta área de estudios. Los aportes de Propp fueron divulgados por Claude Lévi-Strauss (1960) y Algirdas Greimas (1970), quienes formaron parte de la escuela francesa junto a otros investigadores importantes como Roland Barthes, Gérard Genette, Claude Brémond y Tzvetan Todorov, todos ellos autores de muchas de las obras clásicas del análisis estructuralista que concibe el texto como una entidad autónoma, y a quienes se adeuda el alto grado de solidez actual de las bases teóricas sobre la narración como género literario. Con ellos se configuró la 'Narratología': una disciplina dentro de los estudios literarios enfocada al análisis de la estructura interna de los relatos, con la aspiración de derivar las leyes que rigen la creación narrativa, al margen de variantes culturales, contextuales, temporales, etc., es decir, la obra artística como entidad autónoma.

Un cambio de enfoque se inició con la teoría de los actos de habla, de la escuela anglosajona: John Austin (1962) y John Searle (1969) llamaron la atención sobre la necesidad de considerar las intenciones y objetivos de los hablantes en el análisis de los enunciados, es decir, el contexto situacional, lo cual, aplicado a la obra literaria implicó verla dentro de un circuito comunicativo más amplio que el de los análisis tradicionales centrados en el autor o la obra. Adam y Lorda recuerdan que ya en los años treinta Mijaíl M. Bajtín (1982, 1986, 1989), había postulado la naturaleza intersubjetiva de los usos 
lingüísticos, en su teoría sobre la mente dialógica y la novela polifónica, y que el antropólogo Bronislaw Malinosky (1974) había elaborado una teoría pragmática del lenguaje, que incluía una consideración de las funciones sociales de las narraciones. Todas estas ideas darían lugar a elaboraciones nuevas que reivindican el papel de lector y demás elementos que condicionan la 'producción' de una obra artística en general, y que fueron argumentadas con especial dedicación en torno a las manifestaciones literarias narrativas: Hans Robert Jauss (1967), con su estética de la recepción; Umberto Eco $(1962,1979)$ con sus nociones de lector modelo y cooperación interpretativa; Pierre Bourdieu (1992) y su teoría sociológica del campo de producción cultural; y las reflexiones desde una perspectiva filosófica de Paul Ricœur (1975).

En alto contraste con la tradición estructuralista e incluso con estos autores arriba mencionados, la investigación sociolingüística de Labov (1966) brindó un aporte trascendental al investigar la estructura narrativa en la producción oral espontánea, es decir, en la conversación de personas corrientes, en lugar de privilegiar las obras elaboradas, ya sea orales o escritas, antiguas o contemporáneas, como espacio de estudio, con lo cual demostraron una mayor coherencia con esas ideas sobre la relevancia de la situación comunicativa para comprender las funciones que producen ciertos tipos de enunciados. Con los resultados de su estudio fue posible "reconocer la capacidad narrativa de los hablantes como una función de su interacción, del interés personal de unos por los otros, como una manifestación de competencia verbal y como un modo de diversión [y sobre todo] el valor del sentido del relato -por qué se cuenta, con qué fin-, que pierde su razón de ser si no se responde a una intencionalidad con relieve y significación en el contexto en que se encuentra" (Calsamiglia, 2000: 13-14).

Sin abandonar la orientación pragmática, el estudio de Adam y Lorda es muestra precisamente de otra perspectiva desde la cual lo narrativo es estudiado: la lingüística textual. En esta tradición, los trabajos de E. Werlich (1975) constituyen la base sobre la cual J. M. Adam (1992) elaboró una propuesta de clasificación de tipos textuales que actualmente goza de amplia aceptación en el campo educativo. En general, los teóricos de la tipología textual ven en la narración la forma discursiva de pautas más regulares, en contraste con otras (argumentación, descripción, exposición), y se ha reconocido como 
una forma elocutiva diferenciada por su proceso cognitivo característico, su morfosintaxis, su función discursiva y unas marcas lingüísticas propias (Bordons, 1993, 3).

En sintonía con el espíritu de la investigación sociolingüística de Labov, no por casualidad Adam y Lorda titulan la introducción a su libro "Los relatos y la vida". En las indagaciones teóricas que hemos revisado (de los narratólogos, de los didáctas de la literatura, en especial sobre la literatura infantil y juvenil, y los lingüistas textuales como ellos), encontramos ya como un lugar común que se empiece por aludir a esta presencia e importancia universal de la narratividad en la comunicación, como "acción humana fundamental" y, por ende, abundante en todas las culturas: “...las obras en las que el relato domina destacan cuantitativamente en el conjunto de las producciones literarias, de las que constituyen, probablemente, las formas más populares" (Adam y Lorda, 1999: 11). Los autores destacan su manifestación por sobre la diferencias culturales (por ejemplo: en la parábola bíblica y los cuentos filosóficos); por sobre las variantes de formato (en el mito, la fábula, los cuentos policíacos); por sobre las variantes de composición (en el diseño cronológico o de intrahistorias); por sobre la diferencia funcional (para la parodia, la elegía, o el registro histórico como en las crónicas de Indias); incluso, por sobre las formas verbales, ya que cualquier representación simbólica puede tener una organización narrativa: el dibujo, la pintura, el teatro, el cine, etc.

Con todo ello, los autores buscan posicionar su concepción de lo narrativo no simplemente como un tipo de texto, ni siquiera un tipo de discurso, sino como un modo psicológico de organización de los enunciados, ya sea orales, escritos y no verbales, y además demostrar que no es una realidad simple, de rasgos claramente diferenciables, sino un modelo heterogéneo entre cuya diversidad es posible identificar aquello que es el 'aire familiar' de todas sus manifestaciones (Adam y Lorda, 1999: 12-13).

En una orientación similar, Carlos Lomas y Amparo Tusón (2000) ejemplifican cómo, sin duda, pensamos narrativamente en la mayoría de órdenes de nuestra vida: en la conversación espontánea cotidiana por supuesto, espacio donde lo perciben primero los niños; en la publicidad, en los chistes, en las canciones, en la predicción (como en los oráculos antiguos, y el horóscopo y la meteorología actuales), en 
los juicios, en las noticias, los videoclips, y el discurso científico, ya que se ha utilizado para explicar metafóricamente el funcionamiento químico de los elementos o los procesos biológicos de nuestro cuerpo. Incluso añaden como ejemplo el relato de la historia personal que subyace a la organización del currículum vitae.

En fin, podemos resumir que se trata de la forma primaria de organización de las ideas que los seres humanos saben usar para pensar y producir discursos, en torno a asuntos vitales: la explicación del sentido de nuestra existencia en el mundo, la explicación de ese mundo y, en función de lo anterior, la educación de las nuevas generaciones, la organización de la vida cotidiana presente, la reflexión de cómo fue en el pasado y la proyección de cómo puede ser en el futuro, así como la imaginación de mundos ficticios, con lo cual se convierte además en medio de placer. De hecho, contar historias para el disfrute es una de las profesiones más antiguas: desde los aedas griegos, pasando por los juglares medievales, hasta los cuenta-cuentos contemporáneos. Podemos decir que la narración "es uno de los modos del discurso monologal que más arraigo tiene en la mente humana y que funciona como esquema de compresión y de interpretación más básico. Esta es la razón de que haya sido tan profusamente estudiado desde las más diversas perspectivas" (Calsamiglia, 2000:10).

\section{Lo que nos cuenta la Neuropsicología}

En este punto queremos abordar los planteamientos derivados de la Psicología cognitiva para destacar las bases orgánicas que subyacen en la forma narrativa del lenguaje, con el fin de destacar una manera de entender la narración ya no solamente como forma literaria sino que también en sus implicaciones para el desarrollo cognitivo. Intentaremos para ello resumir esos descubrimientos 'revolucionarios' sobre el funcionamiento de la mente humana, para enfatizar cómo la interacción con otras personas mediante el lenguaje ocupa un papel central, especialmente en su realización narrativa.

Empezaremos por las teorías de Lev Semenovich Vigotsky (18961934) sobre el desarrollo de los conceptos desde la tierna infancia hasta la adolescencia, que formuló en sus investigaciones sobre el aprendizaje como proceso interno de construcción del conocimiento, 
de elaboración y manipulación de significados, y el papel del lenguaje en dichos procesos. Estas teorías fueron ampliadas posteriores por Alexander R. Luria (1902-1977) quien colaboró con Vigotsky y luego continuó la misma línea de investigación en neuropsicología.

En síntesis, estos investigadores rusos constataron que la actividad neuronal observa una organización específica según el funcionamiento lingüístico, es decir, según los actos de habla o escritura que la persona realice mediante el uso de un lenguaje. Vigotsky estableció unas categorías para designar las etapas por las que evoluciona esta actividad neuronal según se va manifestando en las formas en que el niño usa el lenguaje verbal (sincretismo, conceptos complejos, pseudoconceptos, conceptos genuinos). Por su parte, Luria estableció dos tipos de organización neuronal que subyacen a dos tipos de comportamiento lingüístico: uno que corresponde a un uso contextualizado de la lengua, es decir, con un fuerte apoyo en la información referencial, con relaciones secuenciales entre las ideas y por ello en torno a un eje sintagmático, propio del tratamiento de asuntos de la experiencia cotidiana, para la comunicación de acontecimientos. El otro corresponde a un uso descontextualizado de la lengua, en el que predominan las relaciones lógicas entre las ideas, con una organización jerárquica en torno a un eje paradigmático, de uso preponderante para tareas intelectuales y científicas. Este es el nivel de la 'gramática experta' (Halliday, 1986), es decir, mecanismos lingüísticos que han sido posibles con apoyo en la escritura, para compactar los significados de una forma que se facilite su manipulación en el razonamiento académico y científico. Esta organización categorial representa una acumulación semántica donde se sobreentienden relaciones básicas, de la información referencial, y permite pasar a relaciones semánticas más complejas (Lomas y Ruiz, 2003: 7-8), las del eje paradigmático en la explicación de Luria, y los conceptos genuinos para Vigotsky.

Las personas pueden lograr el dominio de ambos niveles pero, mientras el primero se desarrolla y adquiere en la comunicación de la vida familiar y social, de forma espontánea y no formal, el segundo requiere de un entrenamiento dedicado que añade el uso de un instrumento tecnológico adicional: la lengua escrita, lo cual no supone la sustitución total de una capacidad por otra, sino una existencia complementaria y alternada según la funcionalidad que exigen los 
contextos comunicativos.

Lo cierto es que muchas teorías sobre el desarrollo del lenguaje en el campo de la neuropsicología desembocan en un mismo fenómeno: el relato (las definiciones de Vigotsky sobre los complejos en cadena y los 'pseudoconceptos'; los estudios sobre el dibujo infantil que empiezan por una etapa de 'relatos gráficos'; la definición de Luria sobre el eje sintagmático para la organización de acontecimientos en oposición al eje paradigmático (Luria, 1995); el postulado de Bruner sobre la narración como el principio organizativo de la psicología popular, en oposición al pensamiento lógico-científico (2002). La conclusión general que podemos extraer es que la forma narrativa del lenguaje se sostiene sobre una actividad cerebral específica, que se desarrolla a temprana edad por el contacto con los hablantes, contrario a lo que ocurre, digamos, con la forma ensayística la cual se aprende posteriormente y de manera sistemática. En palabras de Fayol (1985): la narración constituye de hecho "una organización cognitiva prelingüística muy general” (en Calsamiglia, 2000: 13).

En cuanto a las ventajas de este tipo de desarrollo cognitivo, Wells (1986) demostró que el contacto con relatos desde la temprana infancia tenía una influencia positiva en el aprendizaje de la lengua escrita porque es el mecanismo mediante el cual "el niño empieza a descubrir la potencialidad simbólica del lenguaje: su poder para crear mundos posibles o imaginarios por medio de la palabra" (Colomer, 1998: 73). Y gracias a las investigaciones sobre la comprensión lectora, con apoyo en el legado teórico de la narratología que ya reseñamos, se logró establecer científicamente que la asimilación mental del esquema narrativo se domina muy rápidamente, y que este conocimiento es el que permite la comprensión y memorización de los relatos.

Teresa Colomer (1999) describe esta evolución en su investigación sobre la literatura infantil y juvenil: a partir de los 18 meses, se comprende la representación simbólica de la realidad mediante imágenes (dibujos, fotografías, etc.), además aprende significados culturales de las cosas representadas (bueno, malo, bonito, feo, seguro, peligroso, etc.). Luego, a los dos años se empiezan a utilizar en la actividad lúdica recursos convencionales (juegos con las palabras, el pretérito imperfecto, tonalidades de la voz, personajes estereotípicos). Colomer explica que el progreso gradual de los niños en su 
adquisición de conocimientos formales sobre cómo se relata es mayor en los aspectos del esquema narrativo, los personajes y los temas. En cuanto al esquema, aprenden poco a poco a establecer relaciones causales entre los sucesos, proceso en el que Applebee (1978) ha identificado seis formas básicas, que se corresponden aproximadamente con la evolución descrita por Vigotsky: la primera estructura narrativa es simple, una asociación de una idea a otra; a los cinco años dominan la cadena focalizada, que es la relación de acciones en torno a un personaje; a los seis años ya se llega al dominio de la estructura propiamente narrativa, en todos sus aspectos y que implica establecer la secuencia del tipo inicio-nudo-desenlace (Applebee, 1978: 23-24).

Las investigaciones en neuropsicología continúan y abarcan otros aspectos de estudio, como los procesos de elaboración del significado; así se ha llegado a reconocer que a través del contacto con los relatos, se construye un significado personal que supone el efecto educativo esperado por los adultos, asunto sobre el cual queremos profundizar.

\section{Las funciones educativas de los relatos}

En un inicio hemos mencionado lo que serían las funciones generales de la forma narrativa en la vida, al grado que es muy difícil ordenarlas por un orden de prioridad: todas en conjunto son importantes. Pero requerimos profundizar en algunas de ellas por sus implicaciones educativas, sobre todo cuando ocurren mediante las manifestaciones literarias de la forma narrativa: llámese relato, cuento, tradición oral, mito, historia, leyenda... representación simbólica a fin de cuentas. Para facilitar el análisis, en lo sucesivo utilizaremos 'relato' como término abarcador.

Empecemos por recordar el indiscutible atractivo de los relatos tanto en la edad infantil como la adulta, lo cual parece inherente a la naturaleza humana: "La capacidad de contar y la posibilidad para mayores y pequeños de divertirnos, conocernos mejor y aprender gracias a los relatos tiene carácter universal" (Adam y Lorda, 1999: 13). Agustín Fernández también reconoce que la necesidad curiosidad o placer - por las historias no nos abandona nunca (2000: 24), y en palabras de Colomer: "El deseo y la curiosidad por el relato están presente en todas las edades y éste se puede presentar bajo 
Narración y desarrollo cognitivo: el potencial didáctico de una alianza neurolingüística

múltiples formas" (1998: 10).

A lo anterior se debe sumar que ha sido a través del relato que todas las culturas han reflexionado sobre el sentido de su existencia, han dado una explicación, y han procurado educar en función de estas creencias a las nuevas generaciones; es decir, el relato también ha servido para preservar esa ontología fundacional de todo grupo humano, ya que lo que no se fija narrativamente (de forma oral o escrita), no se queda en la memoria (Bruner, 2002: 66).

Sin duda, contar cuentos es el recurso más connatural de los padres para educar a sus hijos. Este uso del relato en la interacción con propósitos educativos, dirigido por los adultos es, en otras palabras, la transmisión de la cultura, entendida en el sentido antropológico. Además, tal y como lo demostró Vigotsky a través su tesis sobre la ley general del desarrollo cultural, esa transmisión se realiza con la participación activa y creativa de ambas partes, los portadores del legado cultural y sus receptores.

De hecho, la reflexión sobre el significado de la existencia se repite cada vez en la ontogénesis, según lo demostraron los estudios desde el psicoanálisis: cada niño experimenta una angustia existencial que el contacto con los relatos ayuda a canalizar y superar positivamente. Uno de los principales exponentes de esta área, Bruno Bettelheim (1997), explica ampliamente la importantísima función de los relatos en la maduración psicológica y configuración de la personalidad de los niños:

“El niño necesita que se le dé la oportunidad de comprenderse a sí mismo en este mundo complejo con el que tiene que aprender a enfrentarse, precisamente porque su vida, a menudo, le desconcierta. Para poder hacer eso, debemos ayudar al niño a que extraiga un sentido coherente del tumulto de sus sentimientos. Necesita ideas de cómo poner en orden su casa interior $\mathrm{y}$, sobre esta base, poder establecer un orden en su vida en general. Necesita [...] una educación moral que le transmita, sutilmente, las ventajas de una conducta moral, no a través de conceptos éticos abstractos, sino mediante lo que parece tangiblemente correcto y, por ello, lleno de significado para el niño. El niño encuentra este tipo de significado a través de los cuentos de hadas" (1997: 11). 
La reflexión existencial del niño ocurre de forma indirecta, proyectada en la fantasía, en las vivencias de los personajes con los cuales se identifica por afinidad. Y ciertamente, no puede hacerlo a través del lenguaje lógico-categorial, simplemente porque en su cerebro aún no se ha desarrollado la organización neuronal que sirve de base para efectuar tales actos lingüísticos del pensamiento racional, por tanto, no puede aprender la ética a través del discurso categorial sino hasta que haya avanzado en la escolaridad con el dominio de la lengua escrita. Bettelheim añade además que esta eficacia formativa de los relatos maravillosos radica en que conectan directamente con los estados emocionales de los niños: tratan de los fuertes impulsos internos e inconscientes que en la proyección de la fantasía se pueden confrontar más fácilmente para su comprensión, por la cercanía subjetiva pero exteriorizada que conllevan escucharlos o leerlos, además, ofrecen resoluciones a grandes tensiones al ilustrar la manera de salir adelante en las dificultades.

De lo anterior podemos concluir que la creación y transmisión de la literatura de Tradición Oral, sobre todo en comunidades ágrafas, constituye una actividad crucial en la formación personal y social: "los mitos y la épica en general ofrecen las primeras respuestas a muchos de los eternos problemas de la existencia, ya que reducen la complejidad de la vida cotidiana a series simbólicas de formas y elecciones". Applebee lo explica en otros términos:

"las historias pueden ayudar a crear expectativas sólidas sobre cómo es el mundo y cómo se habla sobre él sin necesidad de evaluar y contrastar su realidad. Cuando los niños aprenden que las historias son ficción, asimilan que lo son únicamente en su especificidad, mientras que los esquemas de valores recurrentes, las expectativas estables que forman parte de la cultura propia han pasado ya a configurar sus esquemas de conocimiento. Son esos esquemas implícitos [...] los que convierten a las historias en un importante agente de socialización, una de las muchas maneras a través de las cuales las nuevas generaciones adquieren los valores y normas de los adultos" (Colomer, 1998: 76).

Este es el aspecto de nuestro mayor interés: cómo tiene lugar esta 'misión' de los relatos en la transmisión del legado cultural. Los niños aprenden a enfrentar y construir su propia experiencia a partir de los 
significados que los relatos le proporcionan, y con base en ello participan de la vida social. Obtienen los datos sobre el comportamiento humano que subyacen en las peripecias de los héroes, las princesas, las brujas, los enanos, los objetos mágicos, etc. Esto demuestra que la mente opera en el seno de una cultura, en su existencia lingüística, por lo que la mejor manera de asimilar las reglas del juego es en contacto y uso de esas manifestaciones del lenguaje que resultan accesibles tempranamente para la capacidad cognitiva del ser humano: los relatos. Es así como se perciben las coordenadas culturales de forma implícita, inconsciente si se quiere, desde una posición interna y subjetiva, es decir, una relación íntima con lo narrado, con el lenguaje y por ende con la cultura, en lugar del distanciamiento objetivo que supone por ejemplo escuchar una exposición o leer historia, el almanaque o una guía turística.

A este trato íntimo con la cultura a través de los relatos y los significados que resultan y son interiorizados por nuestro modelo de mundo, incidiendo en su configuración, es decir, afectando nuestra manera de ver las cosas, podemos llamarle modelaje lingüístico de la conciencia (Cantero, 1998). Este fenómeno neurolingüístico busca fundamentar el uso programado de los relatos en la escuela, aprovechar ese potencial de la literatura para explicar la cultura desde dentro, subjetivamente, y procurar un aprendizaje intercultural significativo, es decir, que además de servir para conocer la diversidad cultural mediante el contacto con relatos de la diversidad, también sirva para adquirir los recursos que permitan tratar con esa diversidad de forma acertada. Nos referimos al desarrollo de la competencia intercultural, el conjunto de habilidades cognitivas, afectivas y prácticas necesarias para desenvolverse eficazmente en ambientes donde confluyen personas de diferentes culturas, lenguas, etnias o nacionalidades (Aguado, 2003). Un comportamiento eficaz incluye la capacidad de sentir empatía, de resolver dificultades de comunicación, de poder interpretar y comprender las otras maneras de ser y pensar, de analizar las diferencias y puntos en común, de mediar y negociar en momentos de conflicto, e incluso capacidad para obtener un sentido equilibrado de la propia existencia en el contacto intercultural.

Para reforzar la valoración de la literatura de Tradición Oral para la educación intercultural, citaremos las apreciaciones de Pilar Núñez (2005: 193) ya que coinciden con los intereses de nuestra investigación. 
Esta autora llama la atención en cómo este subgénero de la literatura ha perdido valor simbólico y espacio concreto ante el campo ganado por la Literatura Infantil, a pesar de ser su claro antecedente, y critica a la institución escolar por descuidar una de sus funciones básicas: "la socialización y la inserción de los niños en su cultura por medio de la valoración de sus tradiciones".

Núñez (1995) propone que la literatura de Tradición Oral se rescate para su aprovechamiento en los nuevos contextos de la educación literaria y lingüística, ya que ha pasado por un proceso de adaptación a la modernidad por el contacto de intercambio con la cultura letrada, de manera que ha cambiado sus funciones y causes de transmisión (de hecho se transmite por escrito) y se ha convertido en un potente intertexto temático y discursivo.

Por ello, la autora invita a "delimitar las estrategias didácticas más convenientes para lograr los fines de transformación integral y cultural que persigue la educación literaria", y expone sus cualidades, como por ejemplo: su carácter lúdico que la hace consustancial al mundo infantil y permite desarrollar múltiples aspectos: el afianzamiento emocional y afectivo, el desarrollo cognitivo, la maduración perceptiva y el pensamiento creativo e imaginativo (Núñez, 1995: 193).

Para explicar con exactitud los aprendizajes que tienen lugar mediante el contacto con los relatos (incluido el que particularmente nos interesa promover: la competencia intercultural), podemos utilizar como guía la propuesta de Agustín Fernández, quien distingue cuatro dimensiones: lingüística, ideológica, catárquica y creativa (2000: 2425). La primera tiene que ver con el aprendizaje instrumental de la lengua y de su estructura gramatical de forma implícita. El uso de los relatos en la educación formal debe dirigirse a facilitar el paso de los esquemas narrativos al nivel de los esquemas lógico categoriales, mediante la introducción paulatina de textos de la lengua escrita de mayor complejidad. En palabras de Lomas y Ruiz (2000: 8): “Enseñar a leer desde la educación infantil hasta la universidad implica ayudar a desempaquetar esos concentrados conceptuales" propios de la gramática experta antes aludida. Este proceso requiere de especial atención cuando se trabaja con usuarios de lenguas ágrafas o que hasta época reciente han sido dotadas de su forma escrita, por lo cual, 
Narración y desarrollo cognitivo: el potencial didáctico de una alianza neurolingüística

aún no se han desarrollado para el pensamiento abstracto, en el eje de las relaciones paradigmáticas. Por lo tanto, bajo el lema de la atención a la diversidad, un docente debe estar muy atento a reconocer estas características de la competencia lingüística de sus alumnos, para saber conducirlos óptimamente a desarrollar los siguientes estadios en su desarrollo cognitivo.

\begin{abstract}
“La adquisición de la competencia narrativa es un proceso cada vez más complejo, con momentos fronterizos que deberían tratarse con delicadeza en cada caso personal, favoreciendo el tránsito a formas más elaboradas y a la representación de experiencias en consonancia con la maduración lingüística -de la oralidad, la lectura y la escritura narrativas - y la maduración personal" (Calsamiglia, 2000: 19).
\end{abstract}

Este propósito educativo adquiere una trascendencia social importantísima, porque el dominio de una gramática experta implica la adquisición de unas competencias comunicativas que habilitan para participar en el mercado lingüístico con mayores oportunidades de éxito.

En la segunda dimensión, Fernández se refiere al modelo de mundo que cada lengua porta y que se manifiesta tanto directa como indirectamente. Más aún, puesto que los relatos son un producto cultural en sí mismos, pueden revelar los discursos sociales sobre cómo educar, y cómo se concibe la infancia. Ciertamente, los relatos ofrecen la posibilidad de múltiples aprendizajes ideológicos porque nos hacen escuchar voces distintas, es decir, facilitan entrar en contacto con diferentes formas de ver el mundo, de representarlo literariamente, de sentirlo.

Varios recursos técnicos viabilizan esta dimensión pero entre ellos la voz narrativa es especialmente importante porque es el elemento mediador entre los hechos que se narran y el lector, la que invita a que éste se ubique en una determinada posición respecto a los acontecimientos: "la voz traduce, en su forma de ver el mundo, una dimensión social e histórica que puede ser más o menos coincidente con la del lector" (Colomer et al., 2005: 73). Cuando el lector prefiere una u otra opción, está reaccionando ante la valoración moral de la conducta humana que toda visión de la realidad incluye. Llamar la 
atención sobre esta actuación es importante, para que los niños asuman las consecuencias de sus opciones, que aprendan que los hechos se pueden evaluar desde un punto de vista, pero que existen otros, con otras implicaciones.

Con los personajes nos encontramos ante el principal vehículo de los valores transmitidos, ya sea del ideal de persona que se precia como deseable para una sociedad, así como vitrina de las conductas descalificadas. Su eficacia se debe a que "son la principal baza de la ficción para crear su ilusión de realidad, de manera que los lectores juzgan la coherencia y verosimilitud de un relato fundamentalmente por las características y acciones de éstos" (Colomer et al., 2055: 119). Los personajes son el medio principal para efectuar esa gran cualidad de la ficción de ampliar y enriquecer la experiencia inmediata, y conocida, hacia lugares, épocas y mentalidades desconocidas y lejanas (o muy cercanas en el caso de países con población inmigrante). La posibilidad de ser otro sin dejar de ser uno mismo, es decir, de multiplicar la experiencia propia a través de la vivencia de los personajes y la oportunidad de explorar la conducta humana de modo comprensible, gracias a la imaginación, ofrece ventajas potentes para la educación intercultural porque a través de los personajes se entra en otras conciencias, se puede experimentar la sensación de estar en los zapatos del otro otro y así desarrollar la capacidad de empatía. Para Clive Staples Lewis: "La experiencia literaria cura la herida de la individualidad, sin socavar sus privilegios [...] me convierto en mil personas diferentes si dejar de ser yo mismo" (Colomer et al., 2005: 119). Conociendo personajes diversos, el niño crea expectativas sobre su papel en la sociedad, porque asimila el imaginario colectivo sobre una serie de estereotipos, personajes literarios clásicos, o históricos, modélicos, "el modo de ser -y de querer ser" de cada sociedad, los cuales sin duda inspiran nuestro comportamiento inconscientemente, para actuar, solucionar nuestros dilemas, saber escoger (Colomer, 1999: 46,125).

Precisamente la dimensión catárquica se refiere a esta ayuda de los relatos en la maduración psicológica, que ya explicamos antes con las ideas de Bettelheim. Cabe añadir únicamente el matiz que adquieren dichas ideas en una situación multicultural, porque seguramente las pulsiones internas sobre la propia identidad que afronta un niño se duplican. La ayuda de los cuentos maravillosos (y, en especial, sus 
versiones recicladas de la época contemporánea, políticamente correctas), tendrán mucho que aportar para fortalecer la autoestima individual, la seguridad en relación al valor de la propia diferencia cultural, y la misma valoración y respeto por la cultura de los otros.

La cuarta dimensión ofrece un apoyo clave a esta dimensión anterior, porque con el desarrollo de las potencialidades creativas, lo exótico, lo ajeno, lo diferente se vuelve cercano, conocido, familiar. La capacidad de imaginar otros mundos posibles, conlleva imaginarse a sí mismo en la piel de otro, ser otro sin dejar de ser uno mismo, y esta ampliación de la experiencia es una de las cualidades más potentes de la ficción, como ya se mencionó. Además, Vigostky demostró en sus estudios sobre la imaginación creativa cómo esta capacidad ocupa un lugar básico en la condición humana: todo lo que hacemos es un acto de creación en el sentido más amplio, por lo cual fomentarla en un área, repercute en el comportamiento intelectual general.

Esperamos que estas reflexiones no dejen dudas de que "los intercambios literarios son una forma privilegiada del diálogo entre culturas" (Obiols, 2004: 58), y que, por lo tanto, son un instrumentos idóneo para la formación de la competencia intercultural en la escuela. En el marco de un enfoque curricular intercultural para el sistema de la educación básica, el objetivo es promover que los imaginarios, las lenguas, los valores, las costumbres de otras sociedades constituyan una presencia habitual en el horizonte de expectativas de los lectores: que nada humano nos sea ajeno, como decía Terencio (en Moreno, 2001: 15), para que el aula se convierta en verdadero espacio de conocimiento y comprensión de la diversidad así como de crecimiento personal para la convivencia intercultural.

Precisamente, con este artículo hemos querido afirmar el convencimiento en la potente funcionalidad de los relatos de la Tradición Oral para educar y forjar una nueva sociedad sustentada en los principios del enfoque intercultural; uno formulado desde las necesidades y derechos de los pueblos indígenas y afrodescendientes de América Latina, y preocupado por situar en el contexto de las inequidades sociales la discusión sobre el tipo de educación pertinente para estas poblaciones y sus conciudadanos. 


\section{Mapa conceptual: resumen de ideas principales}

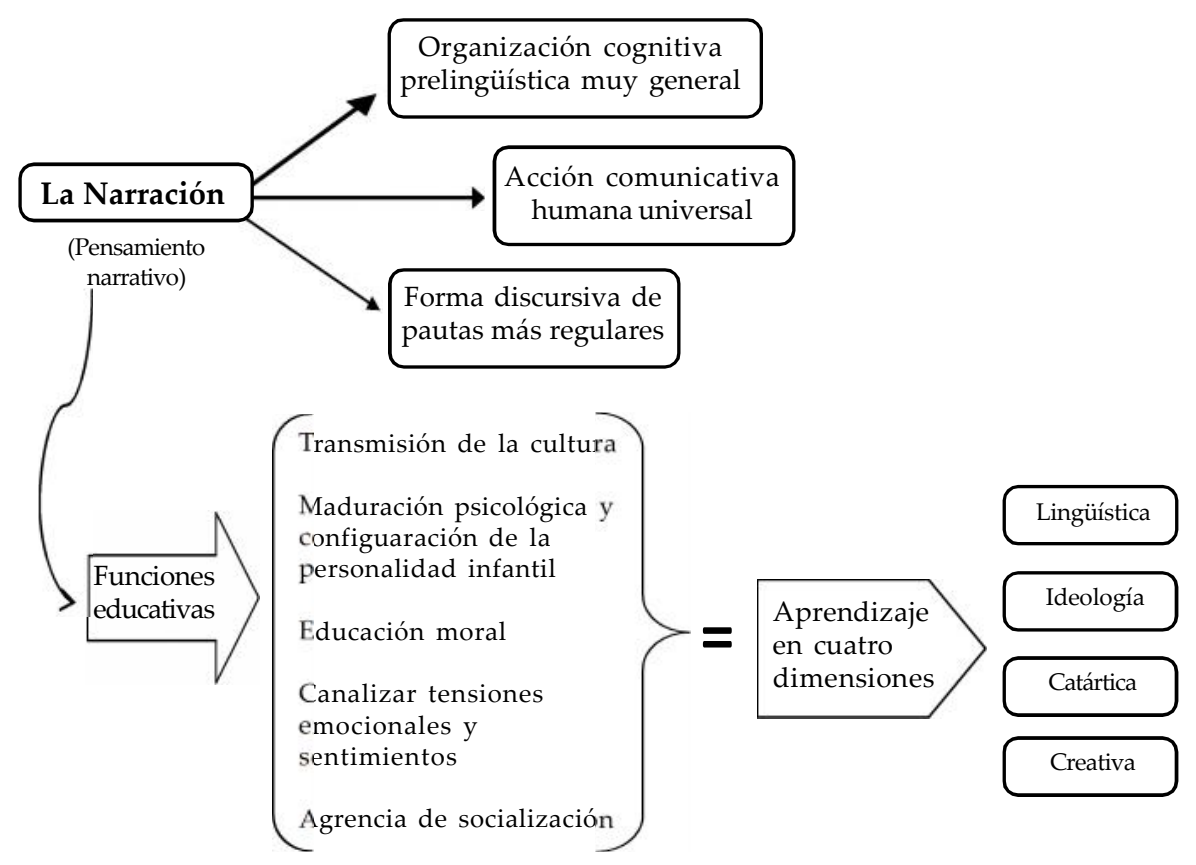


Narración y desarrollo cognitivo: el potencial didáctico de una alianza neurolingüística

\section{Referencias}

Adam, Jean-Michel (1992). Les textes: type et prototypes: récit, description, argumentation, explication et dialogue. Paris: Nathan.

Adam, Jean-Michel y Clara-Ubaldina Lorda (1999): Lingüística de los Textos Narrativos. Barcelona: Ariel.

Aguado, Teresa (2003): Pedagogía Intercultural. Madrid [etc.] : McGraw-Hill.

Austin, J. L. (1962). How to do things with words: the William James lectures delivered at Harvard University in 1955. Cambridge: Harvard University Press.

Bakhtin, M. M. (1989). Teoría y estética de la novela: trabajos de investigación. Trad. Helena S.

Kriúkova y Vicente Cazcarra. Madrid: Taurus.

Bakhtin, M. M. (1986). Problemas de la poética de Dostoievski. México, D.F. [etc.]: Fondo de Cultura Económica.

Bakhtin, M. M. (1982). Estética de la creación verbal. México: Siglo XXI.

Bettelheim, Bruno (1999): Psicoanálisis de los Cuentos de Hadas. Barcelona: Crítica.

Bettelheim, Bruno (1974): Heridas Simbólicas. Los ritos de la pubertad y el macho envidioso. Barcelona: Barral.

Bordons, Gloria (1993): “Els Gèneres Literaris i les Tipologies Textuals: Lògiques Comunes". Butlletí del Cabinet de Didáctica 28: 4-8.

Bourdieu, Pierre (1992): Les Règles de l'art: genèse et structure du champ littéraire. Paris: Éditions du Seuil. Trad. esp. (1995): Las reglas del arte. Génesis y estructura del campo literario. Madrid: Anagrama, 20023. 
Delia María Fajardo

Bruner, Jerome (2002): Actos de Significado. Más Allá de la Revolución Cognitiva. Madrid: Alianza.

Calsamiglia, Helena (2000): “Estructura y Funciones de la Narración”. Textos de Didáctica de la Lengua y la Literatura 25: 9-19.

Cantero, Francisco José y José De Arriba (1997): Psicolingüística del Dicurso. Barcelona: Octaedro.

Colomer, Teresa (1998): La Formación del Lector Literario: Narrativa Infantil y Juvenil Actual. Madrid: Fundación Germán Sánchez Ruipérez.

Colomer, Teresa (1999): Introducción a la Literatura Infantil y Juvenil. Madrid: Síntesis.

Colomer, Teresa (coord.) (2002): Siete Llaves para Valorar las Historias Infantiles. Madrid: Fundación Germán Sánchez Ruipérez, 2005 $1^{\underline{a}}$ reimp.

Eco, Umberto Eco (1979). Lector in fabula: la cooperazione interpretativa nei testi narrativi. Milano: Bompiani.

Eco, Umberto (1962). Opera aperta: forma e indeterminazione nelle poetiche contemporanee. Milano: Bompiani.

Fernández Paz, Agustín (2000): “Estrategias para Contar Cuentos y Escribir Relatos en la Escuela Primaria". Textos de Didáctica de la Lengua y la Literatura 25: 23-33.

Greimas, Algirdas Julien et al (1970). Sign, Language, Culture. Paris: Mouton.

Jauss, Hans Robert (1976). La literatura como provocación. Barcelona: Península.

Labov, William (1966). The social stratification of English in New York City. Washington: Center for Applied Linguistics.

Lévi-Strauss, Claude (1960). La structure et la forme: réflexions sur 
Narración y desarrollo cognitivo: el potencial didáctico de una alianza neurolingüística

un ouvrage de Vladimit Propp. Paris: I.S.E.A.

Lomas, Carlos y Amparo Tusón (2000): “La Narración”. Textos de Didáctica de la Lengua y la Literatura 25: 5-8.

Lomas, Carlos y Uri Ruiz (2003): “Leer y Entender”. Textos de Didáctica de la Lengua y la Literatura 33: 7-10.

Luria, Alexander R. (1995): Conciencia y Lenguaje. Madrid: Visor. Colección Aprendizaje.

Luria, Alexander R. et al. (s.f.): Psicologia e pedagogia. Trad. esp. (1973): Psicología y Pedagogía. Madrid: Akal.

Malinowski, Bronislaw (1974). Magia, ciencia, religión. Barcelona: Ariel.

Moreno, Juan Carlos (2001): “Asombróse un portugués... Prejuicios Lingüísticos y Educación". Textos de Didáctica de la Lengua y la Literatura 26: 5-8.

Núñez Delgado, María Pilar (2005): “Literatura de Tradición Oral y Nuevas Tecnologías en la Educación Literaria Escolar", en Catalina Gonzáles et al.: Leer de nuevo, leer lo nuevo. Barcelona: Grupo Editorial Universitario. 191-200.

Obiols, M. Rosa (2004): “La literatura i l'altre”, en Gloria Bordons y Anna Díaz-Plaja (coords.): Ensenyar Literatura a secundària. La Formació de Lectors Crítics, Motivats i Cultes. Barcelona: Graó.

Propp, Vladimir (1998): Las Raíces Históricas del Cuento. Madrid: Fundamentos.

Propp, Vladimir (1979): Morfología del Cuento. Madrid: Fundamentos.

Ricœur, Paul (1975). Les Cultures et le temps: études préparées pour l'Unesco. Paris: Payot: Presses de l'Unesco.

Ricoeur, Paul (1975). Hermenéutica y estructuralismo. Buenos Aires: Megápolis. 
Searle, John R. (1969). Speech acts: an essay in the philosophy of language. London: Cambridge University Press.

Sartorello, Stefano Claudio. “Una perspectiva crítica sobre interculturalidad y educación intercultural bilingüe: El caso de la Unión de Maestros de la Nueva Educación para México (UNEM) y educadores independientes en Chiapas". En Revista Latinoamericana de Inclusión Educativa, Vol.3, Núm.2. pp.77-90. Universidad Central de Chile - Facultad de Ciencias de la Educación. ISSN Versión impresa: 0718-5480; ISSN Versión Digital: 0718-7378. www.rinace.net/rlei/

Vigotsky, Lev S. (1986). La Imaginación y el Arte en la Infancia. Madrid: Akal, 20066.

Vigotsky, Lev S. (1986). Thought and language. Boston: The Massachussetts Institute of Technology. Trad. Esp. (1995): Pensamiento y Lenguaje. Barcelona: Paidós. 